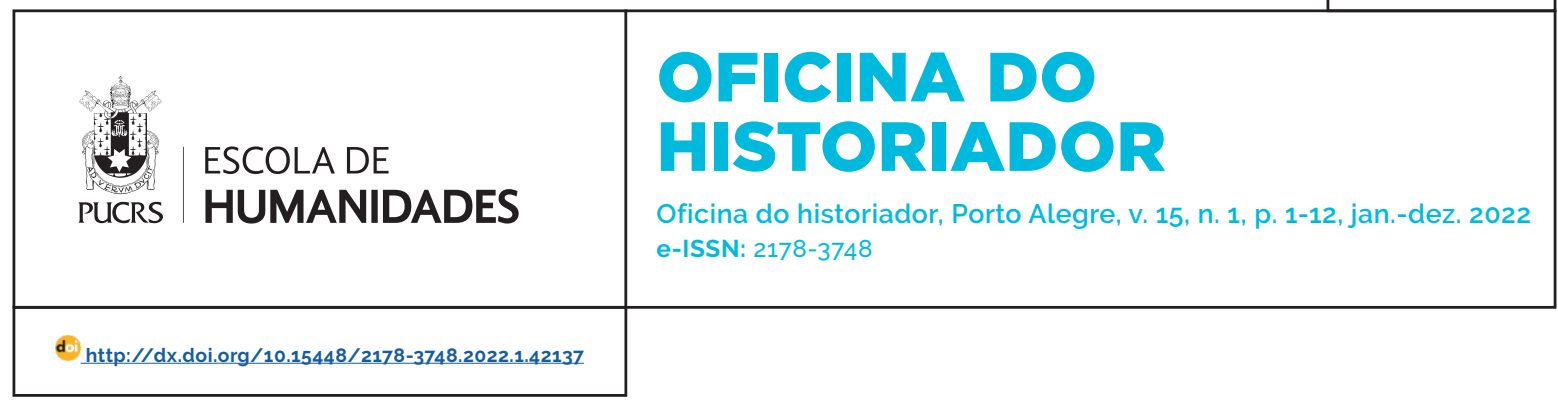

SEÇÃO: ENTREVISTA

\title{
Entrevista sobre o mundo do trabalho com a professora Dra. Melina Perussatto (UFRGS)
}

\author{
Interview about the work studies with professor Dra. Melina Perussatto (UFRGS)
}

\section{Alan Ricardo Schimidt \\ Pereira $^{1}$ \\ orcid.org/0000-0001-6866-5082}

alanricardo.ricardo2@gmail.com

\section{Caio Felipe Gomes}

Violin ${ }^{1}$

orcid.org/0000-0002-5217-100X

caioempreg@hotmail.com

Recebido em: 06 nov. 2021.

Aprovado em: 08 nov. 2021.

Publicado em: $X X X X X . X X X X$.
Resumo: No ano de 2021 foi realizada a presente entrevista com a professora Dra. Melina Perussatto. A entrevista versa sobre o mundo do trabalho, focando nas áreas de especialidade da entrevistada, tais como emancipações e pós-abolição no Brasil, bem como sobre temas da atualidade. A preocupação para a realização da presente entrevista se deu pela necessidade de discutir temas atuais os relacionando com a historiografia, e a necessidade de trazer sempre à tona a questão do mundo do trabalho no Brasil: tema que está sempre muito presente no dia a dia de todos os cidadãos e de constantes debates e múltiplos vieses teórico-metodológicos. Na entrevista, a professora Melina traz suas considerações sobre o tema, e aponta sua própria trajetória acadêmica como um ponto de partida da discussão. Seus aportes de teoria e metodologia são explicados no texto, e suas fontes de pesquisa são abordados para mais lucidações da questão. Através de questões teóricas e de referências acadêmicas, Melina Perussato nos fornece material para reflexão. Uma aula em forma de entrevista é o que aqui é apresentado, nos levando por caminhos da historiografia recente sobre o mundo do trabalho através de um ponto de vista crítico.

Palavras-chave: Mundo do trabalho. Pós-abolição. História social.

Abstract: The following interview was given by professor Dr. Melina Perussato in 2021. The interview deals with the world of work (labor studies), focusing on the interviewee's areas of expertise, such as emancipations and post-abolition in Brazil, as well as current issues related to labor.The interview's concern was the need to discuss current issues of labor relating them to historiography, and the need to constanly bring up the issue of labor in Brazil: a theme that is frequently present in the daily lives of all citizens and is the subject of constant debate and multiple theoretical and methodological approaches. In the interview, Professor Melina brings her considerations about the theme, and present her own academic trajectory as a starting point for the discussion. Her theoretical and methodological contributions are explained in the text, and her research sources are addressed for further elucidation of the issue. Through theoretical questions and academic references, Melina Perussato provides us with reflective content. A class in the form of an interview is what is presented here, taking us along the paths of recent historiography about labor studies through a critical point of view.

Keywords: World of work. Post-abolition. Social history.

Esta entrevista fez parte de uma das atividades desenvolvidas no âmbito da disciplina de Teoria e Metodologia em História Social do Programa de Pós-Graduação em História da PUCRS, no primeiro semestre de 2021. As professoras Marlise Meyrer e Mônica Karawejczyk, responsáveis pela disciplina, distribuiram, entre os alunos, o nome de doutores professores universitários especialistas nas suas áreas de 
atuação, para que fossem entrevistados, como uma das tarefas avaliativas da referida disciplina. Cada um dos professores além de responder a entrevista via e-mail, ministrou uma aula/palestra para a disciplina, e os discentes fizeram a vez de mediadores. Apresentamos, a seguir, a entrevista concedida pela Doutora Melina Kleinert Perussatto (UFRGS) - especialista nas áreas de emancipações e pós-abolição².

Melina Kleinert Perussatto é Doutora em História pela Universidade Federal do Rio Grande do Sul (2018) com periodo sanduíche na Universidade Estadual de Campinas (2016), com a tese Arautos da liberdade: educação, trabalho e cidadania no pós-abolição a partir do jornal O Exemplo de Porto Alegre (c.1892 - c. 1911). A entrevistada também realizou seu mestrado em História pela Universidade do Vale do Rio dos Sinos (2010), com a dissertação Como se de ventre livre nascesse: experiências de cativeiro, parentesco, emancipação e liberdade nos derradeiros anos da escravidão - Rio Pardo/RS, C. 1860 - C. 1888; também é graduada em História-Licenciatura pela Universidade de Santa Cruz do Sul (2008), onde realizou o trabalho Entre a escravidão e a liberdade: alforrias e classificações de escravos no contexto da Lei do Ventre Livre - Rio Pardo/ RS (1871-1888). Atualmente, Melina é professora adjunta na área de Ensino de História do Departamento de Ensino e Currículo da Faculdade de Educação da Universidade Federal do Rio Grande do Sul (DEC-FACED-UFRGS) e credenciada no Programa de Mestrado Profissional em Ensino de História (PROFHISTÓRIA). Também é coordenadora-adjunta do Laboratório de Ensino de História e Educação (LHISTE-FACED-UFRGS) e membro da coordenação colegiada do GT Ensino de História e Educação (GTEH-ANPUH/RS) e da equipe do GT Emancipações e Pós-Abolição (GTEP-ANPUH-BR). Além dessas atividades e da participação em projetos de pesquisa e de extensão, e de GTs (Grupos de Trabalho), a entrevistada também é membro da equipe editorial da Revista Mundos do Trabalho.

Gostaríamos de começar com uma pergunta sobre a sua experiência acadêmica. Ao desenvolver pesquisas sobre o mundo do trabalho envolvendo escravidão e pós-abolição, quais foram as maiores dificuldades que você encontrou? Quais os desafios futuros que os atuais estudantes da área podem esperar encontrar ao se debruçar sobre as fontes?

Iniciei minha trajetória de pesquisa no campo da história social do trabalho por meio de um estudo sobre experiências de escravidão e de liberdade no contexto da Lei do Ventre Livre, tema que ainda suscita discussões sobre as fronteiras temporais e conceituais entre trabalho livre, liberto e escravizado. Os desafios, em termos historiográficos, tornaram-se maiores quando adentrei no pós-Abolição, entendido não apenas como uma cronologia, mas como um problema histórico ${ }^{3}$, originando o campo de estudos sobre o pós-abolição. Se as fronteiras entre os mundos do trabalho livre, liberto e escravizado ainda geram discussões e tensionamentos, a reivindicação da raça e da racialização como categorias de análise entrecruzadas com a classe geram ainda muito mais. Nesse sentido, ao me vincular ao desafio de demonstrar que a raça não é um recorte da classe, mas seu fundamento, somei-me ao conjunto de historiadoras(es) que busca evidenciar e problematizar como a raça foi mobilizada na construção de hierarquias e desigualdades sociais, políticas de dominação e formas de exploração no mundo do trabalho no contexto escravista e no pós-Abolição, mas também na construção de identidades, solida-

\footnotetext{
2 A professora Dra. Melina Perussatto realizou sua aula/palestra no dia 2 de junho de 2021 sobre a temática do Mundo do Trabalho relacionando essa questão típica da História Social com suas experiências de pesquisa e trajetória acadêmica. A entrevista redigida para a professora foi encaminhada no dia 25 de maio de 2021 contendo dez perguntas que versavam sobre sua experiência de pesquisa (teoria, método e percepções pessoais sobre o meio), suas áreas de atuação (escravidão e pós-abolição), sobre história da imigração e questões da atualidade relacionadas ao mundo do trabalho (para serem respondidas a partir de uma perspectiva pessoal e relacionada com as experiências de história social). Essa entrevista foi entregue de volta com as respostas no dia 5 de novembro de 2021.

3 RIOS, Ana Lugão; MATTOS, Hebe Maria. O pós-abolição como problema histórico: balanços e perspectivas. Topoi, Rio de Janeiro, v. 5 . n. 8, p. 170-198, jan./jun. 2004
} 
riedades e lutas. Pessoas comuns, trabalhadores, igualmente disputaram os sentidos da raça 4 .

Esta abordagem tem sido pautada sobretudo por pesquisadoras(es) negras(os) e incorporada nos estudos desenvolvidos no campo da história social do trabalho em virtude dos compromissos políticos assumidos por seus membros. De modo ampliado, o contexto de ataque aos direitos trabalhistas tem intensificado a agenda de pesquisas, debates e mobilizações em torno da compreensão do caráter estrutural da raça (bem como do gênero) nas relações de classe no Brasil. Destaco o pioneirismo de duas pesquisadoras do campo: Beatriz Ana Loner, na virada do milênio, com as discussões sobre a participação de trabalhadores negros na construção da classe trabalhadora a partir de Pelotas e Rio Grande na Primeira República5; e Isabel Bilhão, no começo dos 2000, com as articulações entre gênero e classe na construção de identidades no mundo do trabalho de Porto Alegre no mesmo período ${ }^{6}$. Digo isso para evidenciar que o debate não é novo, mas certamente conta, hoje, com um aparato teórico-metodológico muito mais denso e sofisticado.

Desse modo, embora ainda haja controvérsias, algo comum em qualquer campo, vejo com otimismo a adesão à abordagem que compreende a classe como um fenômeno interseccional - afinal, como nos disse E. P. Thompson, a classe acontece a partir de processos, contextos e relações humanas e históricas ${ }^{7}$ - e um certo abandono da compreensão de que raça e gênero são meramente questões identitárias ou secundárias. Diversos estudos têm demonstrado que, assim como a classe, a raça e o gênero são estruturas e estruturantes do mundo do trabalho no Brasil e que operam entrecruzada e reciprocamente.
No que se refere às fontes, passamos por um momento de profunda transformação decorrente do impacto da digitalização de acervos, bem como dos documentos natos digitais, e isso não se restringe ao campo. Para tanto, é fundamental estreitar o diálogo com a história digital e com as humanidades digitais, restabelecendo critérios de crítica e de manejo de fontes. Outro ponto é a mudança na natureza das fontes. Se a renovação historiográfica registrada a partir da década de 1980 nos estudos sobre escravidão caracterizou-se pelo adensamento da leitura e da interpretação de fontes oficiais (documentos judiciários, eclesiásticos, notariais, administrativos), algo que permeou minha pesquisa de mestrado, as inflexões trazidas pelo campo do pós-abolição trazem consigo o destaque às fontes produzidas a partir dos indivíduos e dos grupos negros, como jornais atas e estatutos de clubes e sociedades e fontes orais.

Nessa esteira, na pesquisa de doutorado, a principal fonte foi um jornal da imprensa negra (e operária, como busquei explicitar) existente em Porto Alegre durante a Primeira República, cujas coleções foram digitalizadas em um projeto coordenado pela professora Maria Angélica Zubaran ${ }^{8}$ e em outro coordenado pelo Instituto Histórico e Geográfico do Rio Grande do Sul (IHGRGS). ${ }^{9}$ Cheguei a manusear alguns originais no Museu da Comunicação Social Hipólito José da Costa (MUSECOM), mas a pesquisa foi centralmente realizada a partir do acervo digitalizado. Complementarmente, a busca nominativa nos acervos da Hemeroteca Digital da Biblioteca Nacional ${ }^{10}$ e do Family Search ${ }^{11}$ foram fundamentais para os rumos e os resultados da pesquisa, permitindo uma filtragem das fontes por palavras-chave. Muito embora tivesse ciência disso, não cheguei

\footnotetext{
4 ALBUQUERQUE, Wlamyra. O jogo da dissimulação. Abolição e cidadania negra no Brasil. São Paulo: Cia. das Letras, 20og; ROSA, Marcus Vinícius de Freitas. Além da invisibilidade: história social do racismo em Porto Alegre durante o pós-abolição. Porto Alegre: EST, 2019. 5 LONER, Beatriz. Construção de classe: operários de Pelotas e Rio Grande (1888-1930). 2. ed. rev. ampl. Pelotas: Editora da UFPel, 2016.

6 BILHÃO, Isabel. Identidade e trabalho: uma história do operariado porto-alegrense (1898-1920). Londrina: EdUEL, 2008.

7 THOMPSON, E. P. A formação da classe operária I. Rio de Janeiro: Paz e Terra, 1987: THOMPSON, E. P. Folclore, antropologia e história social. In: NEGRO, Antônio: SILVA, Sérgio (org.). As Peculiaridades dos Ingleses e outros artigos. Campinas: Editora da Unicamp, 2001. p. 227-268.

8 O projeto e o acervo estão disponiveis em: http://www.ppgecim.ulbra.br/oexemplo. Acesso em: 5 nov. 2021

9 O acervo digitalizado está disponivel em: https://www.ihgrgs.org.br. Acesso em: 5 nov. 2021.

10 Disponivel em: http://memoria.bn.br. Acesso em: 5 nov. 2021.

11 Disponivel em: https://www.familysearch.org. Acesso em: 5 nov. 2021.
} 
a desenvolver uma reflexão ou crítica da fonte, que passa pelos limites dos buscadores digitais utilizados.

Já na dissertação, o máximo de tecnologia, que já era muita coisa na época, era o computador portátil e a câmera fotográfica digital. Fotografei praticamente todas as fontes utilizadas, mas sem o recurso de busca nominativa oferecida pelos referidos repositórios, por exemplo. Tive que montar os bancos de dados no Excel para, então, empreender a busca nominativa e as filtragens. Uma vantagem é que essa metodologia me obrigou a ler toda a fonte para localizar o que me interessava, permitindo-me uma visão mais ampliada do documento, algo de que prescindi, e de certa forma perdi, na busca digital realizada na Hemeroteca Digital ou no Family Search.

Fica, enfim, o desafio de avaliar perdas e ganhos dessas novas formas de pesquisar. Dentre os ganhos, destaco as possibilidades abertas não apenas para a busca e o cruzamento nominativo, mas também para a construção de estudos comparativos, conectados, globais, com fontes produzidas em outras localidades e países. Isso, sem dúvidas, vem adensando nossa compreensão sobre a história do trabalho e das trabalhadoras(es) e ampliando as possibilidades de investigação. Dentre os desafios, temos ainda o impacto da escassez e dos cortes de recursos para a pesquisa decorrente dos profundos ataques à educação e à ciência no Brasil.

Do início da sua formação acadêmica até agora ocorreram muitas modificações nos estudos envolvendo o mundo do trabalho no Brasil? Qual a situação desse tipo de estudo hoje no campo da historiografia?

Sim, houve muitas modificações, mas também continuidades, como já apontei brevemente na questão anterior. Não vou dar conta de uma resposta ampliada, então vou apontar algumas impressões desde o meu ponto de vista.

As continuidades referem-se à permanência da centralidade da análise de experiências, agências, negociações e resistências de trabalhadoras(es) frente aos sistemas normativos, às relações de poder, bem como à delimitação, à constituição e ao comportamento dos grupos sociais, passando pelo estudo da cultura política, das sociabilidades cotidianas, das alianças e dos conflitos em seu interior, da leitura e da interpretação do mundo pelas(os) trabalhadoras(es) a sua volta e de sua própria situação. Ou seja, a partir de E. P. Thompson ${ }^{12}$, permanece o entendimento de que a experiência conecta, tensiona e modifica a relação entre sujeito e estrutura; e de que as(os) trabalhadoras(es) e seu ponto de vista ocupam um lugar fundamental na compreensão da história e da sociedade, em caráter dialógico, processual, relacional.

Dentre as modificações, destaco o impacto dos tensionamentos dos estudos do pós-abolição nas discussões registradas, pelo menos, desde a década de 1990 sobre a "transição" do trabalho escravizado para o livre, a coexistência de trabalho livre e escravizado antes de 1888 e o "muro de Berlim" historiográfico entre os estudos sobre escravidão e trabalho livre ${ }^{13}$. Os estudos sobre o pós-abolição, articulados à história social do trabalho, vêm enfrentando, por exemplo, o desafio de identificar e de problematizar a existência de trabalhadoras(es) negras(os) no mundo do trabalho livre posterior à Abolição, pautando a indissociabilidade de raça e de gênero na análise do mundo do trabalho no Brasil e da construção da classe trabalhadora.

Simultaneamente, desde pelo menos os anos 1990, a confluência da história social do trabalho com a história das mulheres e os estudos de gênero pautam a necessidade de se compreender a divisão sexual do trabalho e/ou a generificação

\footnotetext{
12 THOMPSON, E. P. A Miséria da Teoria ou um planetário de erros: uma critica ao pensamento de Althusser. Rio de Janeiro: Jorge Zahar Editores, 1981

13 LARA, Silvia Hunold. Escravidão, cidadania e história do trabalho no Brasil. Projeto História, São Paulo, n. 16, p. 43-56, fev. 1998; BATALHA, Cláudio. Os desafios atuais da história do trabalho. Anos 90, Porto Alegre, v.13, n. 23/24, p. 87-104, jan./dez. 2006; NEGRO, Antônio Luigi; GOMES, Flávio dos Santos. Além de senzalas e fábricas: uma história social do trabalho. Tempo Social: revista de sociologia da USP, São Paulo, v. 18, n. 1, p. 217-240, 2006; CHALHOUB, Sidney Chalhoub; SILVA, Fernando Teixeira. Sujeitos no imaginário acadêmico: escravos e trabalhadores na historiografia brasileira desde os anos 1980. Cadernos AEL, Campinas, v. 14, n. 26, p. 14-47, 2009.
} 
do trabalho, indo além dos estudos sobre o trabalho reprodutivo. Os direitos das mulheres e a maternidade, nesse sentido, também são temas de destaque nos estudos sobre os mundos do trabalho ${ }^{14}$. E articulado aos debates do campo do pós-abolição, há um crescente volume de pesquisas atentas às intersecções de gênero, raça e classe, com destaque aos estudos sobre escravidão e trabalho doméstico. ${ }^{15}$

O campo do pós-abolição trouxe a interseccionalidade, oriunda do feminismo negro, para o centro do debate e da análise, também adotada por outros campos. Por meio dela, busca-se adensar a compreensão da situação da exploração sofrida pela mulher negra a partir da análise dos efeitos entrecruzados de gênero, raça, classe, dentre outros marcadores, e construir estratégias políticas de emancipação e justiça social. Mais do que uma reflexão sobre a construção de identidades, portanto, a interseccionalidade visa instrumentalizar políticas públicas e mudanças sociais, considerando raça, gênero e classe como estruturas e estruturantes. Aplicada à história social do trabalho, a interseccionalidade permite-nos complexificá-la e renová-la, concorrendo para uma releitura de fontes já tradicionais, como a imprensa e os processos judiciais, bem como para a interpretação sobre as experiências dos sujeitos históricos de forma alargada.

Esses novos estudos apontam a necessidade de se problematizar o padrão, o universal, de modo a se interrogar a masculinidade, a branquitude e a heterossexualidade das(os) personagens que protagonizaram por muito tempo as produções no campo. Nesse sentido, além do feminismo negro, os estudos críticos da branquitude e os estudos decoloniais e pós-coloniais têm impactado sobre a história social do trabalho. Vejo que ainda é necessário avançarmos no que se refere aos estudos sobre branquitude, masculinidade, bem como, complexificando a interseccionalidade ${ }^{16}$, a orientação sexual no mundo do trabalho.

Apenas para ilustrar, em 2016, em uma parceria entre o GT Emancipações e Pós-Abolição e o GT Mundos do Trabalho, ofereci com a Fernanda Oliveira um minicurso no Encontro Estadual da ANPUH-RS, intitulado "Gênero, raça e classe: repensando a história social". O que nos moveu foi a vontade de compartilhar as leituras que estávamos fazendo (Angela Davis, Patricia Hill Collins, bell hooks, Gayatri Spivak, Donna Haraway, Gloria Anzaldua, Ochy Curriel etc.); e de criar um espaço de debate e reflexão sobre a história social. O número significativo de pessoas participantes indicou não só a importância do debate, mas sobretudo a demanda por inflexões historiográficas. ${ }^{17}$

A proposta desse minicurso decorreu das discussões decorrentes das X Jornadas Regionais do GT Mundos do Trabalho - ANPUH/RS, ocorridas em 2015, em parceria com a Unisinos e com o tema "Histórias do trabalho escravo, liberto e livre". ${ }^{18}$ A conferência de abertura, proferida por Álvaro Nascimento, originou um importante artigo sobre a persistência do "paradigma da ausência" na historiografia do trabalho. ${ }^{19}$ Seis anos depois, a discussão segue tanto em âmbito nacional20

14 FRACCARO, Gláucia. Os Direitos das Mulheres: Feminismo e Trabalho no Brasil (1917-1937). Rio de Janeiro: FGV Editora, 2018.

15 Como já são muitos trabalhos, vou citar apenas dois que acompanhei de perto: HAACK, Marina Camilo. Sobre silhuetas negras: experiências e agências de mulheres escravizadas (Cachoeira, c. 1850 -1888). 2019. Dissertação (Mestrado em História) - Universidade do Vale do Rio dos Sinos, São Leopoldo, RS, 2019; SANTOS, Bruna Letícia de Oliveira dos. "Os brancos não falam a verdade contra mim. Porque ele é homem e não havia de passar o trabalho que as fêmeas passam": Maria Rita e a interseccionalidade na experiência de mulheres escravizadas (Comarca de Rio Pardo, século XIX). 2020. Dissertação (Mestrado em História) - Universidade do Vale do Rio dos Sinos, São Leopoldo, 2020

16 SCHMIDT, Benito. Complexificando a interseccionalidade: Perspectivas queer sobre o mundo do trabalho. Revista Mundos do TrabaLho, Florianópolis, v. 10, n. 19, p. 31-41, 2019.

17 A ementa está disponivel em: http://www.eeh2016.anpuh-rs.org.br/minicurso/view?TIPO=1\&ID_MINICURSO=1057. Acesso em: 5 nov 2021.

18 A programação do evento está disponivel em: http://viiijornadasgtmtrs.blogspot.com. Acesso em: 5 nov. 2021.

19 NASCIMENTO, Álvaro Pereira Nascimento. Trabalhadores negros e o "paradigma da ausência": contribuições à história social do trabalho no Brasil. Estudos Históricos, Rio de Janeiro, v. 29, n. 59, p. 607-626, set./dez. 2016.

$20 \mathrm{Um}$ exemplo é a mesa "Raça, gênero e classe na história social do trabalho: visões interseccionais" ocorrida em 2018 durante o $\mathrm{V}$ Seminário Internacional Mundos do Trabalho | IX Jornada Nacional de História do Trabalho | IX Jornadas Regionais do GT Mundos do Trabalho/RS. Disponivel em: https://youtu.be/LZEwyNAhhoo?list=PLSdH6N1ptPJ2e4zcjtucizRboDu7f7deB. Acesso em: 5 nov. 2021 . Vale conferir também a programação do VI Seminário Internacional realizado de forma virtual na página do GT: https://Www.youtube.com/c/ GTMundosdoTrabalho/playlists. Acesso em: 5 nov. 2021 
quanto estadual, ${ }^{21}$ evidenciando sua pertinência para o campo.

Enfim, diversos estudos demonstram que a República brasileira esteve a serviço da construção de desigualdades sociais racializadas e generificadas diretamente vinculadas à constituição da estrutura produtiva e reprodutiva. A confluência de campos evidencia que a classe trabalhadora e a pobreza têm uma cor predominante no Brasil, que homens e mulheres vivenciam suas experiências de formas distintas e racialmente desiguais, que essa realidade foi deliberadamente construída com a conivência do Estado com os grupos dominantes.

Quais diálogos podemos fazer entre as ciências sociais e os estudos historiográficos sobre o mundo do trabalho? Você tem alguma abordagem teórica que prefira ou que predomine nos seus estudos? Existe algum método de sua preferência ao se debruçar sobre as fontes? Com que tipo de fontes você geralmente trabalha?

Há diversos diálogos entre as áreas, mas também disputas, especialmente, por conta do que as particulariza. Trabalho na editoria da Revista Mundos do Trabalho, vinculada ao GT homônimo e à recém-fundada Associação Brasileira de História do Trabalho. Com frequência, recusamos submissões por não seguirem o foco e o escopo da revista que, em resumo, exige que haja trabalho, história e gente. A esse despeito, as análises sociológicas fornecem categorias importantes à reflexão historiográfica e foram fundamentais para a construção desse campo no Brasil.

Em específico sobre a minha abordagem, registro a importância da obra da socióloga Patricia Hill Collins, que densificou a teorização sobre a interseccionalidade, por sua vez utilizada pela primeira vez pela jurista Kimberlé Crenshaw no final dos anos 1980.22 "Imagens de controle"23 e "outsider within"24 são outras categorias importantes fornecidas pela socióloga para o estudo sobre as experiências de trabalho e os pontos de vista das mulheres negras.

Entendo que a demanda atual é a necessidade de darmos densidade historiográfica a essas categorias e conceitos. Isso exige a análise de experiências de sujeitos individuais ou coletivos em determinados contextos, processos e relações. Enfim, entrecruzar classe, raça, gênero, orientação sexual, dentre outros marcadores na análise histórica permite-nos compreender não apenas a construção das diferenças e identidades, mas sobretudo das desigualdades que acometem trabalhadoras(es) ao longo do tempo em diferentes espaços e como forjaram estratégias de luta e resistência.

Ademais, é preciso frisar que a constituição do campo da história do trabalho é tributária a trabalhos sociológicos. Como exemplo, Beatriz Ana Loner, anteriormente citada como uma das importantes referências da história social do trabalho, realizou sua tese de doutorado no Programa de Pós-Graduação em Sociologia da UFRGS. Obviamente, por ser historiadora de formação, seu trabalho centrou-se nas experiências de trabalhadores na construção da classe.

Sobre o método, como historiadora social, a microanálise tem me acompanhado desde o mestrado por viabilizar um tratamento quantitativo e qualitativo das fontes e identificar estratégias, repertórios, escolhas e ações dos sujeitos históricos. Dessa forma, consegui adensar a compreensão das relações entre experiências de sujeitos individuais ou coletivos com o contexto e o processo histórico. Para responder de forma

\footnotetext{
21 Como exemplos, a atividade de lançamento do Grupo de Pesquisa Trabalho, Cultura e Resistência - TRESCULT em 2020. Disponível em: https://youtu.be/1xenlvN_J98. Acesso em: 5 nov. 2021; e o eixo "Classe, raça e gênero nos mundos do trabalho" das XI Jornadas Regionais do GT Mundos do Trabalho, que ocorrerão em novembro de 2021.

22 CRENSHAW, Kimberlé. Documento para o encontro de especialistas em aspectos da discriminação racial relativos ao gênero. Estudos Feministas, Florianópolis, v. 10, n. 1, p. 171-188, jan. 2002, p. 175; COLLINS, Patricia Hill; BILGE, Sirma. Interseccionalidade. São Paulo: Boitempo, 2020.

23 COLLINS, Patricia Hill. Pensamento Feminista Negro: conhecimento, consciência e a política do empoderamento. São Paulo: Boitempo Editorial, 2019.

24 COLLINS, Patricia Hill. Aprendendo com a outsider within: a significação sociológica do pensamento feminista negro. Revista Sociedade e Estado, Brasilia, v. 31, n. 1, p. 99-127, jan./abr. 2016
} 
mais concreta, vou percorrer brevemente minha trajetória de pesquisa.

Interessei-me pelo tema da escravidão e da liberdade negra durante a iniciação científica realizada em projeto vinculado ao Arquivo Histórico Municipal de Rio Pardo (AHMRP), sob a orientação do professor José Remedi, na Unisc. O ano era 2006 e eu estava indo para o final da graduação. Em meio a uma infinidade de documentos, chamou-me atenção aqueles referentes à escravidão, sobretudo diante da narrativa identitária regional sobre o protagonismo teuto e a invisibilidade, ou mesmo a inexistência, da população negra. Tratava-se da documentação produzida pela Junta Municipal de Emancipação de Escravos criada em decorrência da Lei 2.040, de 18 de setembro de 1871, por meio da qual a cota do fundo de emancipação destinada à libertação de pessoas escravizada seria distribuida nos municípios a partir de critérios legalmente definidos. Por meio da tabulação das listas de classificação cheguei a informações sobre a vida de muitas pessoas escravizadas, sobretudo de familias compostas por mães e filhos, bem como suas lutas por liberdade.

Isso me despertou o desejo de conhecer mais sobre essas experiências e, por meio do Catálogo Documentos da Escravidão, produzido pelo Arquivo Público do Estado do Rio Grande do Sul (APERS), pude acessar e tabular informações sobre a vida de outras pessoas e seus processos de libertação. Inspirada sobretudo pelos trabalhos de Sidney Chalhoub e Paulo Moreira, evidenciei a presença histórica de pessoas negras na região. Busquei ainda equilibrar a denúncia sobre a violência da escravidão e a demonstração da agência daquelas pessoas. Ou seja, a despeito das tentativas contrárias, pessoas escravizadas encontraram subterfúgios para preservar sua humanidade.

Tal problemática me levou ao mestrado, cursado com bolsa CNPq na Unisinos, sob a orientação do professor Paulo Moreira, entre 2008 e 2010. Além de adensar o levantamento de fontes, sobretudo daquelas salvaguardadas no APERS (inventários post-mortem) e no Arquivo
Histórico da Cúria Metropolitana de Porto Alegre - AHCMPA (registros de batismo e casamento), investi no cruzamento nominativo de fontes. Foi nesse momento também que me aproximei do GT Mundos do Trabalho da Anpuh e aprofundei o diálogo com a obra de E. P. Thompson.

Por mais óbvio que possa parecer, é fundamental demarcar que pessoas negras eram trabalhadoras no contexto escravista e não deixaram de sê-la após a Abolição. Nesse sentido, a partir de Rio Pardo/RS, a serialização de fontes e a microanálise permitiram-me constatar a dependência da mão de obra de pessoas negras até o último suspiro da escravidão; a coexistência e a convivência de pessoas de diferentes condições juridicas em núcleos familiares e espaços de trabalho; a divisão generificada do trabalho, com predomínio de mulheres nos serviços domésticos e dos homens nos trabalhos agrícolas; a diversidade de ocupações especializadas, tendo algumas pessoas mais de uma especialidade; a existência de familias negras e seus projetos coletivos e familiares de liberdade, que passavam por negociações no âmbito do trabalho; a significativa presença da mão de obra de crianças nascidas de ventre livre, cuja iniciação no trabalho ocorria a partir dos cinco anos de idade. Em meio a isso, narrei diversas trajetórias no intuito de humanizar os dados apresentados.

Diante da centralidade de tais sujeitos e da localização de tutelas em meio a documentos avulsos do AHMRP, no doutorado, cursado com bolsa CNPq na UFRGS, entre 2013 e 2018, pretendia investigar tal questão, articulando liberdade, trabalho e educação no desagregar da escravidão. Por um lado, interrogava como proprietários e autoridades viam na educação uma forma de disciplinar a vida em liberdade e preparar o trabalhador livre e, por outro, como as pessoas nascidas de ventre livre e suas familias reagiam a isso e atribuiam sentidos próprios à liberdade, ao trabalho e à educação. Avançando para o pós-abolição em busca de vestígios, deparei-me com a existência de um projeto educacional gestado por um grupo de intelectuais negros e divulgado por meio do jornal O Exemplo, de Porto Alegre, 
quatro anos após a Abolição. O que era para ser um diálogo, gerou uma mudança profunda no projeto de tese. ${ }^{25}$

Depois de ler artigos, dissertações e teses sobre o periódico, mais do que o interesse em seu projeto, quis saber quem eram as pessoas por detrás do jornal. Desse modo, alterei meu projeto e a microanálise ajudou-me na busca e no cruzamento nominativo de fontes inéditas sobre as trajetórias desses intelectuais e seus familiares. Essa preciosa sugestão, aliás, foi dada pelo meu orientador, Fábio Kühn, que me instigou a ampliar o repertório documental de análise. Assim, realizei uma prosopografia dos três grupos que passaram pelo periódico entre 1892 e 1911 e identifiquei informações sobre suas vidas e relações para além do jornal, incluindo aí o âmbito familiar, laboral e associativo. Constatei que alguns frequentaram escolas e mesmo faculdades, alcançaram prestigiosos cargos no funcionalismo público e patentes da Guarda Nacional, pertenciam ao restrito grupo de eleitores, vincularam-se ao PRR etc. Para isso, além da busca onomástica na hemeroteca digital, método já utilizado em outras pesquisas, utilizei inventários post-mortem, testamentos, processos criminais, registros de nascimento e casamento.

Ao mesmo tempo em que se tratava de tipologias documentais já manuseadas na pesquisa de mestrado, sobretudo no que se refere aos inventários, impactou-me muito o fato de localizar pessoas negras em um lugar incomum nas fontes da pesquisa anterior, qual seja, como proprietários. Esse aprendizado afetou profundamente minha escrita e docência.

Hoje estou produzindo um livro paradidático sobre o jornal $O$ Exemplo com o intuito de ampliar a divulgação da minha e de outras pesquisas e assim subsidiar a compreensão das experiências negras para além da escravidão e da subalterni- dade. Como nos convoca Ana Flávia Magalhães Pinto, precisamos realizar exercícios cognitivos e reposicionar o lugar da liberdade das pessoas negras na história do Brasil e da diáspora. ${ }^{26} \quad 0$ projeto conta com uma equipe bastante ampliada e espero que renda boas reflexões e práticas docentes. ${ }^{27}$ Tal expectativa decorre do excelente retorno que tivemos sobre outro paradidático. ${ }^{28}$

Gostariamos, também, de fazer uma pergunta sobre o mundo do trabalho do individuo escravizado no século XIX. Com base nas suas pesquisas para a sua dissertação de mestrado sobre "experiências de cativeiro, parentesco, emancipação e liberdade nos derradeiros anos da escravidão" em Rio Pardo-RS, em que sentido a formação de familia por parte dos escravizados pode ser entendida como uma forma de resistência? Quais as agruras que o trabalho forçado impunha a estas familias?

A familia permitia àquelas pessoas construir uma dignidade humana possivel, afetos, identidades em meio a um sistema a serviço de sua desumanização. Ou seja, a familia era uma forma de existir enquanto gente, e reivindicar essa condição era, em si, uma agência e um ato de resistência. Nesse sentido, é importante frisar que, a partir de E. P. Thompson, entendo a agência como a capacidade dos seres humanos agirem diante das condicionantes sociais que, apesar de condicionarem, não reduziam aquelas pessoas à escravidão. A agência não é condição suficiente para a resistência, mas certamente é uma condição necessária. Nesse sentido, compreender a constituição de família como resistência implica, dentre outras coisas, compreendermos de forma mais acurada suas escolhas, ações, projetos e estratégias.

O trabalho como parte fundamental da vida

\footnotetext{
25 O projeto inicial da tese foi retomado no seguinte artigo: PERUSSATTO, Melina. O futuro da nação: instrução, educação e racialização da infância (Porto Alegre, RS, c. 1871-1910). Revista Brasileira de História \& Ciências Sociais, Rio Grande, v. 13, n. 25, p. 60-90, 2021.

26 PINTO, Ana Flávia Magalhães. Escritos de liberdade: literatos negros, cidadania e racismo no Brasil oitocentista. Campinas: Editora da Unicamp, 2018.

27 Alguns materiais estão sendo divulgados por Jonas Silveira da Silva, acadêmico do curso de História e bolsista do projeto, em: instagram.com/jornaloexemplo. Acesso em: 5 nov. 2021.

28 SILVA, Fernanda Oliveira; AMARAL, Sarah; SÁ, Jardélia; ROSA, Marcus; COSTA, Luciano; PERUSSATTO, Melina; SANTOS, Sherol. Pessoas comuns, histórias incriveis: a construção da liberdade na sociedade sul-rio-grandense. Porto Alegre: UFRGS; EST Edições, 2017.
} 
humana desde as primeiras organizações sociais tornou-se um instrumento de controle, mas também de emancipação e autonomia. Operando a análise nessas tensões, podemos perceber como, a despeito do trabalho forçado e desumano imposto pela escravidão, pessoas escravizadas e seus parentes viram nele possibilidades de libertação, de construção de dignidade. Como exemplo, a reivindicação e o direito costumeiro à roça própria evidenciam significados do trabalho associados à autonomia e à elaboração de projetos de liberdade. Com isso não quero minimizar ou romantizar as condições degradantes e precárias de trabalho, os adoecimentos e ferimentos, a alimentação insuficiente, a ausência de estrutura sanitária ou os maus-tratos, tampouco a perversidade por detrás da submissão das crianças desde a tenra idade ao trabalho ou da separação familiar por meio da venda ou da morte violenta. Mas o fato é que as relações e formas de trabalho carregam consigo uma dialética que não pode ser atenuada ou desconsiderada.

A dissertação da Bruna Letícia dos Santos, por exemplo, explorou os sentidos subjacentes ao infanticídio praticado por Maria Rita em Rio Pardo na década de 1850. Ao ser interrogada sobre porque havia tirado apenas a vida das filhas meninas, ela disse que o menino não passaria pelo sofrimento do trabalho das fêmeas. Ao invés de submeter Maria Rita a um tribunal moral, Bruna articulou trabalho e maternidade em perspectiva interseccional para compreendê-la em sua humanidade e como pensadora. Desse modo, uma fonte já tradicional, como é o caso dos processos criminais, foi considerado pela historiadora como o registro do pensamento de uma mulher negra sobre sua condição e realidade social, histórica e cultural, marcada por todo o peso da exploração escravista. ${ }^{29}$ Ademais, essa situação densifica e complexifica nossa compreensão sobre a família, bem como as relações entre agência, resistência e humanidade.

\section{Quanto ao pós-abolição no Rio Grande do}

\section{Sul, levando em consideração as pesquisas realizadas para sua tese de doutorado, que teve o jornal $O$ Exemplo como foco, quais seriam as opções de inserção no mundo de trabalho para os indivíduos negros? Como isso se dava em ralação à mão de obra imigrante? Em especial, no período entre 1888 e 1930 ?}

O estudo focal no grupo de $O$ Exemplo permitiu-me vislumbrar uma miriade de ocupações que permitiam inserções profissionais e aprendizados diversos: havia tipógrafos, cirurgiões-barbeiros, farmacêuticos, músicos, professores, advogados e muitos funcionários públicos na redação ou no entorno do periódico. Minha intenção foi evidenciar a presença negra em espaços de trabalho para além da precariedade, explicitar a inserção de pessoas negras em profissões que exigiam estudo, contestar a narrativa ainda vigente sobre a incompatibilidade do negro à sociedade de classes e problematizar a centralidade da estratégia de inserção no funcionalismo público por meio de concurso. Mas, a esse despeito, também argumentei que a inserção em profissões menos precárias não thes garantia viver uma vida confortável, exercer sua cidadania com tranquilidade (que passava por circular pelos espaços públicos), uma vez que o racismo produzia (e ainda produz) diversas interdições cotidianas e institucionais.

Como exemplo, o proprietário da barbearia onde o jornal foi fundado em 1892, localizada em um imóvel na rua dos Andradas, faleceu em 1909 em uma meia-água na rua 28 de Setembro, antiga rua dos Pretos Forros, região de muita pobreza e precariedade. Dario de Bittencourt, neto de Aurélio Viríssimo de Bittencourt, o mais emblemático funcionário público da Primeira República, precisou de caridade para se manter no curso de Direito na Faculdade fundada por seu pai e avô. Em sua autobiografia, Dario disse ter deixado de frequentar aulas na década de 1920 por não ter vestuário adequado. O que quero dizer com o isso também é que, apesar de todos os esforços, eles eram insuficientes para 
garantir uma vida digna e confortável. Por isso, a ideia de "elite negra" é insuficiente para descrever a condição desses sujeitos, cabendo-lhes meIhor adjetivações como "intelectualidade negra" ou, ainda melhor, grupo de pessoas instruidas. Embora não tenha registrado na tese, reduzir a intelectualidade à instrução acaba por deixar de fora uma miríade de intelectuais não alfabetizados que igualmente teceram projetos, análises e visões de mundo.

Outra argumentação central ao longo da tese foi a de que o jornal $O$ Exemplo era um jornal negro e operário desde a sua fundação. Estudos anteriores apontaram que essa caracteristica passou a existir somente na primeira década do século XX em virtude do ingresso de militantes socialistas e anarquistas na redação. No entanto, por ocasião de seu primeiro aniversário, em 1893, jornais de maior circulação adjetivaram $O$ Exemplo como um periódico de proletários, que advogava os interesses dos proletários. Nesse sentido, além do mundo do trabalho ser um tema constante, identifiquei a participação de Marcilio Freitas, primeiro gerente do jornal, na diretoria da Sociedade Tipográfica também em 1893. Enfim, O Exemplo também se empenhou em demonstrar que a população negra permaneceu trabalhadora no pós-abolição e engajou-se nas lutas por direitos e nos processos de formação da classe trabalhadora, demarcando a indissociabilidade de raça e de classe. Isso fica ainda mais evidente no manifesto de refundação, de 1902, ao argumentarem que $O$ Exemplo ressurgiu diante da necessidade de reunir "toda essa classe de homens de cor preta, de infelizes trabalhadores, alquebrados ao peso do labor e amesquinhados pela ação dos preconceitos",30

Sobre a relação com os imigrantes, outros estudos sobre o pós-abolição no espaço urbano porto-alegrense apontam que nas disputas por trabalho e moradia, as(os) imigrantes geralmente levavam a melhor. Como exemplo, os anúncios de jornal manifestando a preferência por trabaIhadoras domésticas brancas para ocuparem um espaço de trabalho historicamente ocupado por mulheres negras ${ }^{31}$, bem como a expulsão da população negra do centro ou dos arrabaldes a eles mais próximos, como era o caso da região pejorativamente adjetivada como Colônia Africana e que hoje é uma das áreas mais brancas e valorizadas da cidade.

Sobre esse processo de racialização do espaço urbano, com ênfase nas disputas no mercado de trabalho e nos espaços de moradia, recomendo a tese de Marcus Vinicius de Freitas Rosa..$^{32}$ Outra contribuição dessa pesquisa reside na compreensão de como os "de baixo" manejaram a racialização, ou seja, como ideias de raça circularam entre trabalhadoras(es) negras(os) e brancas(os), proporcionando aos últimos a obtenção de vantagens. Enfim, a situação na qual se encontram as pessoas negras não é consequência exclusiva da ação do poder público e suas instituições ou das elites. Ela contou e ainda conta com a ação e a aquiescência das pessoas comuns, de pessoas brancas.

$\mathrm{Na}$ história da imigração brasileira, temos a vinda de muitos europeus para o Brasil fugindo do percalço das guerras e da pobreza. Atualmente, o processo imigratório mudou, indivíduos de outras nacionalidades estão vindo para o Brasil atrás de oportunidades fugindo da pobreza, de desastres naturais etc., como os bolivianos, haitianos, entre outros e, nesse contexto, temos, muitas vezes, uma nova forma de exploração de mão de obra análoga à escravidão imposta a esses imigrantes. Que paralelos podemos tecer entre este fenômeno e a imigração empreendida no século XIX e início do século XX no Brasil?

\footnotetext{
30 Aprofundei essa discussão em: PERUSSATTO, Melina. O Exemplo, um jornal do povo: imprensa, trabalho e racialização no pós-abolição (Porto Alegre, 1892-1911). In: SPERANZA, Clarice Gontarski; SCHEER, Micaele. (org.). Trabalho, democracia e direitos: mundos do trabalho, identidades e cultura operária. Porto Alegre: Editora Fi, 2019. v. 2, p. 65-94.

31 SANTOS, Mauricio Reali. Gênero, raça e classe: as possibilidades de inserção das mulheres no mercado de trabalho doméstico em Porto Alegre no pós-abolição (1896-1908). 2013. 57 f. Trabalho de Conclusão de Curso (Graduação em História) - Universidade Federal do Rio Grande do Sul, Porto Alegre, 2013.

32 O livro oriundo dela já foi mencionado.
} 
Como não trabalho com o tema da imigração e há muitas(os) especialistas, não me arrisco a responder de forma comparativa. O que posso dizer, do ponto de vista que trabalho, é que nos processos imigratórios do século XIX pessoas brancas foram privilegiadas em detrimento de pessoas negras ou asiáticas dentro nos projetos imigrantistas, que se associaram a projetos de branqueamento populacional. Isso não quer dizer que as(os) imigrantes tiveram uma vida fácil, mas certamente não é comparável com a situação vivida pelas pessoas negras que foram arrancadas de seu continente para serem escravizadas. Imigrantes alemães, inclusive, inseriram-se na economia escravista e tornaram-se proprietários de gentes, como atestam diversos trabalhos realizados na Unisinos desde os anos 2000 (Marcus Tramontini, Eliége Moura, Raul Cardoso, Paulo Moreira e Miqueias Mugge). Ademais, considero complicado adjetivar como escrava a forma de trabalho exercida pelos imigrantes europeus no século XIX. Talvez o mais adequado seja o uso de noções de trabalho coercitivo, forçado, não remunerado, precário.

Sobre o trabalho dos imigrantes na atualidade, há diversos estudos que manejam os conceitos de trabalho análogo ao de escravo ou trabalho escravo contemporâneo para diferenciá-lo da escravidão negra moderna em virtude de suas singularidades (ver as pesquisas de Angela de Castro Gomes e Norberto Ferreras, por exemplo). Se há algo em comum com a imigração europeia, temos a busca por melhores condições de vida. No entanto, haitianos, bolivianos ou senegaleses não são sujeitos desejáveis, ainda que qualificados, virtuosos e talentosos, por não se encaixarem no ideal de brancura que ainda nos preside. Temos, pois, um longo processo de racialização da imigração que precisa ser mais bem investigado.

Acompanhamos em 2020, através dos principais meios de comunicação e de muitos outros, o caso do menino Miguel, que faleceu após cair do nono andar de um prédio de luxo em Recife (Pernambuco). Mirtes de Souza, mãe de Miguel, era funcionária da casa da primeira-dama do municipio de Tamandaré (Pernambuco). Quando Mirtes foi levar os cães da patroa para passear, por descaso e irresponsabilidade da patroa, o menino sofreu a queda. Miguel era um menino negro, assim como sua mãe, e a patroa era uma mulher branca de uma elite social. Tivemos também o caso de Madalena Gordiano que chocou o Brasil. Madalena, uma mulher negra, que trabalhava como diarista na casa da familia Milagres Rigueira e se viu, finalmente, livre da situação em que se encontrava há 38 anos, em regime análogo à escravidão em Patos de Minas, MG, hoje vive feliz e só recentemente pode comemorar seu primeiro aniversário. Você poderia tecer alguns comentários sobre o papel da população negra nos dias de hoje com relação ao mundo do trabalho, relacionando com experiências históricas nas quais os negros sofreram com as agruras do descaso e do preconceito neste mesmo meio?

As pessoas negras seguem sendo a base da estrutura produtiva no Brasil e o topo dos indices de violência policial, de escassez de direitos básicos, de morte violenta. É isso que a Coalisão Negra por Direitos nos disse quando publicou em 2021 o manifesto "Com racismo não há democracia" ou quando nos convocou para os atos no dia 13 de maio de 2021 com o lema "Nem bala, nem fome, nem covid. O povo negro quer viver!".

Para tentar responder à pergunta de forma mais específica e propositiva, e tendo em vista que atuo no Ensino de História, um ponto de contato entre a minha pesquisa e as questões do nosso tempo reside na importância do trabalho intelectual e civilizatório de pessoas negras ao longo de nossa história. Recentemente, todo o conjunto de políticas de ações afirmativas nos trouxe a oportunidade de repactuarmos o projeto de nação desde uma perspectiva radicalmente democrática, equitativa, solidária e humana. A qualificação profissional mediada pela Universidade estava recém-dando os primeiros resultados quando o país sofreu com o golpe de 2016 . 
agravado pelas eleições de 2018, que alçou ao poder um projeto de destruição não apenas das pequenas conquistas registradas, mas também da vida de trabalhadoras(es), aliás, pessoas, em sua maioria, negras.

A ampliação das oportunidades formativas às pessoas negras impacta diretamente na luta antirracista em suas mais diferentes frentes, incluindo ai a possibilidade de projeção de futuro pelas crianças negras, que passaram a se ver em profissões nas quais não estavam acostumadas. Ao ocuparem tais espaços, passam a repensá-los e tencioná-los desde dentro, concorrendo para importantes mudanças. Nesse sentido, uma crítica consiste na redução da atuação das pessoas negras ao tema do racismo, como se elas não existissem, pensassem ou produzissem para além dele. Enfim, é fundamental que sejam valorizadas e reconhecidas em sua pluralidade, que também possam tratar dos ditos temas universais. Nessa esteira, outra reflexão importante vem de Maria Aparecida Bento e seu trabalho no CEERT.33 Por meio do conceito "pacto narcísico"34 ela aponta a cumplicidade estrutural estabelecida entre as pessoas brancas e seu impacto no mercado de trabalho. Ela escancara as relações entre branquitude e desigualdades raciais e aponta a necessidade das pessoas brancas que se entendem antirracistas agirem e utilizarem seus espaços de privilégio em prol de mudanças.

Talvez o grande desafio colocado para nós, pessoas brancas, seja justamente esse: mobilizarmos os recursos materiais e simbólicos que dispomos na luta pela transformação dos privilégios que usufruímos em direitos extensivos a todas as pessoas, desafio, aliás, que está posto para quem ocupa espaços normativos de gênero, sexualidade etc. Dentre outras coisas, nessa repactuação precisamos aprofundar nosso conhecimento sobre as epistemologias, projetos e lutas de pessoas e coletividades negras. Essas ações passam, ainda, pelas eleições, mas não se reduzem a elas. Apostar na educação, como nos ensina o "movimento negro educador", pode ser um importante caminho de luta e emancipação.

Por fim, agradeço às professoras Mônica e à Marlise pelo convite; à turma pela agradável conversa; ao Alan e ao Caio pela entrevista e compreensão; à Bruna Letícia dos Santos, à Marina Haack e o ao Vinícius Masseroni pela leitura, conversa e revisão atenta.

\section{Alan Ricardo Schimidt Pereira}

Graduado em História pela Universidade Luterana do Brasil (ULBRA), em Canoas, RS, Brasil. Mestrando em História pela Pontificia Universidade Católica do Rio Grande do Sul (PUCRS), em Porto Alegre, RS, Brasil.

\section{Caio Felipe Gomes Violin}

Mestrando em História pela Pontifícia Universidade Católica do Rio Grande do Sul (PUCRS), em Porto Alegre, RS, Brasil; Mestrando em Arquitetura e Urbanismo pela Pontificia Universidade Católica de Campinas (PUC-Campinas), em Campinas, SP, Brasil; professor da escola pública de Ensino Médio, em Campinas, SP, Brasil.

\section{Endereço para correspondência}

Alan Ricardo Schimidt Pereira/ Caio Felipe Gomes Violin Pontificia Universidade Católica do Rio Grande do Sul Escola de Humanidades

Av. Ipiranga, 6681, Prédios 8 e 9

Partenon, 90619-900

Porto Alegre, RS, Brasil

Os textos deste artigo foram revisados pela Poá Comunicação e submetidos para validação do(s) autor(es) antes da publicação. 